\title{
Radiographic Features of Osteogenesis Imperfecta about a Female Sibship
}

\author{
B. M. A. Tiemtore-Kambou ${ }^{1,2^{*}}$, A. M. Napon ${ }^{1,3}$, N.-A. Ndé-Ouédraogo',2, A. Koutou ${ }^{2}$, I. F. N. Sieba ${ }^{2}$, \\ I. Ouédraogo' ${ }^{1}$ O. Diallo1,4, R. Cissé1,4 \\ ${ }^{1}$ Joseph Ki Zerbo University, Ouagadougou, Burkina Faso \\ ${ }^{2}$ Bogodogo Teaching Hospital, Ouagadougou, Burkina Faso \\ ${ }^{3}$ Charles de Gaulle Pediatric Teaching Hospital, Ouagadougou, Burkina Faso \\ ${ }^{4}$ Yalgado Ouedraogo Teaching Hospital, Ouagadougou, Burkina Faso \\ Email: ^kbenildema@yahoo.fr, napon.madina@gmail.com,ninawed@hotmail.com, koutouaime@yahoo.fr, isieba@yahoo.fr, \\ iouedraogo@yahoo.fr, odiallo75@yahoo.fr, ciss.rabi@gmail.com
}

How to cite this paper: Tiemtore-Kambou, B.M.A., Napon, A.M., Ndé-Ouédraogo, N.-A., Koutou, A., Sieba, I.F.N., Ouédraogo, I., Diallo, O. and Cissé, R. (2020) Radiographic Features of Osteogenesis Imperfecta about a Female Sibship. Open Journal of Medical Imaging, 10, 52-61.

https://doi.org/10.4236/ojmi.2020.101005

Received: December 6, 2019

Accepted: March 17, 2020

Published: March 20, 2020

Copyright $\odot 2020$ by author(s) and Scientific Research Publishing Inc. This work is licensed under the Creative Commons Attribution International License (CC BY 4.0).

http://creativecommons.org/licenses/by/4.0/

\begin{abstract}
Osteogenesis imperfecta (OI) belongs to a group of congenital osteoporosis which hallmark feature is "affecting skeleton, increasing bone fragility that fracture easily and decreasing bone density due to quantitative and/or qualitative abnormalities". We report a female sibling's involvement in 3 cases with probable recessive inheritance pattern. Only female aged between 5 and 13 years were affected with skeletal lesions in the lower limbs. The boy of this family had no skeletal or extra-skeletal lesions. Their parents had no affection and no bond of consanguinity. The observed malformations can be classified as type V or VI according to Sillence's clinical classification. Lack of genetic test in our context has limited accuracy of the diagnosis as new data evoke a genetic classification into 12 types that leading an effective therapeutic management.
\end{abstract}

\section{Keywords}

Osteogenesis Imperfecta, Familial Involvement, Female, Radiological Features, Recessive Mode

\section{Introduction}

Osteogenesis imperfecta (OI), commonly called "brittle bone disease", is a rare disorder of heterozygous connective tissue caused by mutations in genes that express collagen [1]. Osteogenesis imperfecta is characterized by decreased bone density, bone fragility and skin hyperlaxity. The phenotype present is determined by mutation on the affected gene as well as type and location of that mu- 
tation. OI is neither preventable nor treatable.

It is a genetic disorder characterized by occurrence of mutations in type 1 collagen gene [2]. In most cases, transmission is autosomal dominant [3]. Research data from the Reference Center for constitutional Bone Diseases, OSCAR stream-December 2016 gives a new classification that of the classification of different types of imperfect osteogenesis according to Sillence [4] and the International Nosology of Diseases bone [4].

Its incidence is between 1 in 10,000 and 1 in 20,000 births [6] [7]. This disease affects both sexes without any particular geographical distribution. Excessive bone transparency and deformities on X-ray images are observed [6]. In Burkina Faso, many cases of OI have been reported, but no family involvement has been found in literature. We report this female sibship occurrence based on three (3) cases with probable recessive inheritance pattern.

\section{Cases Report}

Ms. Z., 36 years old is mother of 5 children including 4 girls and 1 boy. She does not present any skeletal or extra-skeletal malformation. Her last 4 children have same father. There is no relationship of consanguinity between parents of these children. The father of the last four children is 7-year-older than the mother.

B. F., 19, is the eldest among Ms. Z children. He does not show any skeleton deformation.

These three children were received at the radiology department for X-ray of the pelvic limbs. Faced with the lesions observed, we decided to do a more in depth exploration of the thoracic limbs and thorax. The skull x-ray was also requested and performed. The children were not on treatment. They came for consultation accompanied by a medical student on behalf of an association which dealt with the surgical management of these rare cases. We asked to see the whole family to support our diagnosis and obtain parental consent. The children were all at school with absences from counseling sessions or pain due to fracture.

\section{Case report 1}

Z. Z., 13 years old, weighs $30 \mathrm{~kg}$ for $128 \mathrm{~cm}$. She is the eldest of the last 4 children. She does not have any particular prenatal history. She reportedly had left humerus fracture at Day 1 of life and one of right shoulder bones fracture that benefited from orthopedic treatment. Then right femur fractures occurred at Day-10 of life as well as left leg bones which would have benefited from a traditional treatment. Physical examination showed deformity of right leg with shortening of ipsilateral limb (Figure 1(A) and Figure 1(B)). Dentinogenesis was normal and sclera was clear. Calcium and phosphate levels were normal. Vitamin D determination showed a vitamin status with 25 hydroxy vitamin D levels at $10.08 \mathrm{ng} / \mathrm{ml}$. Plain films performed showed rarefaction of bone matrix, left femur and right leg bones had a curved appearance; also noted was deformation of $2^{\text {nd }}$ to 6 th left posterior rib arches (Figures $2(A)-(C)$ ). Rest of the skeleton was normal in appearance. 


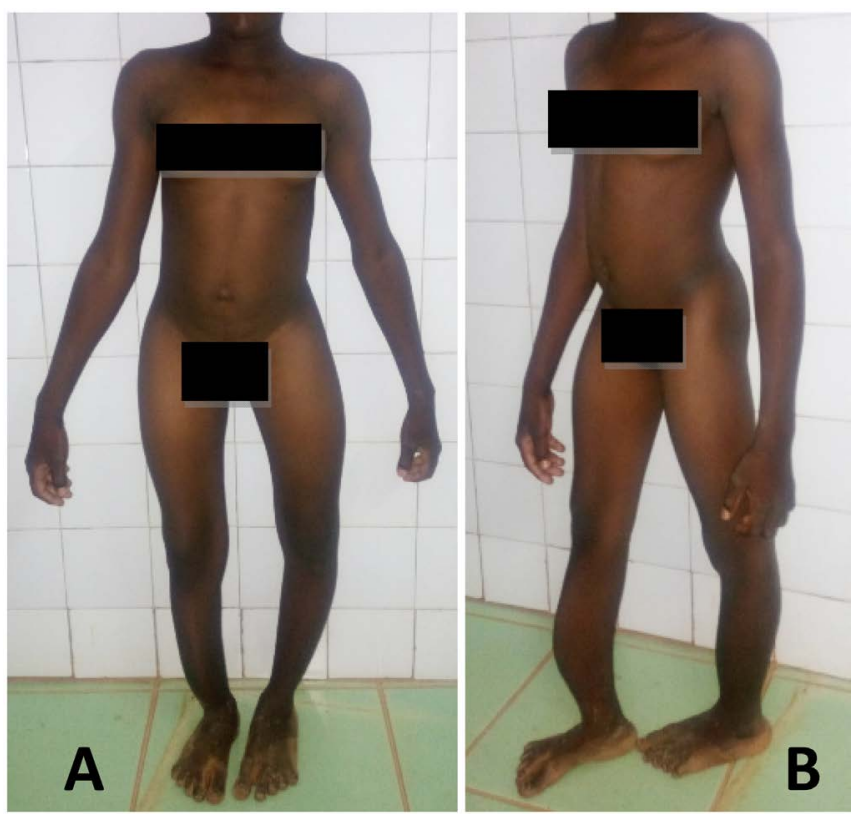

Figure 1. (A) and (B) showing bone deformities and lengthening of left upper limb that reaches knee level, shortening of right upper limb, curved aspect of right leg.
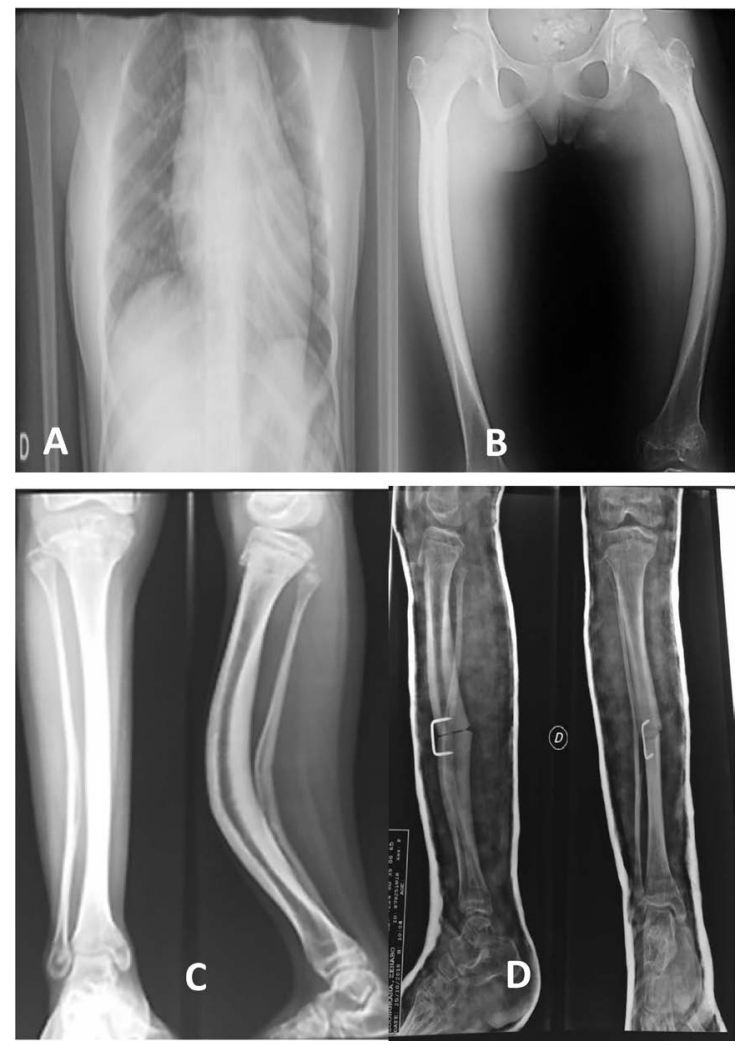

Figure 2. (A) Chest plain film, frontal view: tiny aspect of left posterior ribs; (B) Femurs $\mathrm{X}$-ray frontal view: shortening of the left thigh with curved aspect of the ipsilateral femur and metaphyseal demineralization; (C) Right leg X-ray frontal and lateral views: tiny and curved aspect of both tibia and fibula diaphysis (plastic deformation). Cortical thinning at metaphysis and epiphysis levels; (D) Post-surgery: osteotomy with clip on right tibia under plaster. 
Treatment consisted of a stapling osteotomy on right tibia (Figure 2(D)).

\section{Case report 2}

Z. O., 9-year-old weighed $22 \mathrm{~kg}$ for $114 \mathrm{~cm}$. She is Z. Z's direct younger sister. She had a feet deformity since birth and her first fracture that occurred at age of 3 was treated by traditional way. Clinical examination showed thorax and both pelvic limbs deformity associated with right pelvic limb shortening (Figure 3(A) and Figure 3(B)). Sclera was white and dentinogenesis showed no abnormality. Calcium and phosphate levels were normal. Vitamin D determination showed a vitamin status with 25 hydroxy vitamin D levels at $15.54 \mathrm{ng} / \mathrm{ml}$. Chest X-ray showed deformity of 4th, 5th and 6th right posterior rib arches (Figure 4(A)). $\mathrm{X}$-rays of the limbs showed more diffuse bone demineralization in the metaphyseal-epiphyseal region of the long bones as well as curved aspect of long bones of pelvic limbs more pronounced on the right. Lower limbs bones showed bowing aspect and consolidated fracture with bony callus at $2 / 3$ upper and $1 / 3$ lower junction of right tibia with non-displaced transverse line. Deformation of articular surfaces of the knees and ankles has also been demonstrated (Figures 4(B)-(E)).

The treatment consisted of an osteotomy with pin and staple on both feet superimposed with plaster cast (Figure $4(\mathrm{~F})$ ).

\section{Case report 3}

Z. A. was 5 years old, she weighed $11 \mathrm{~kg}$ for a height of $93 \mathrm{~cm}$. She is the youngest of the family. She was born after an 8-year-old boy, who weighed $19 \mathrm{~kg}$ for 117

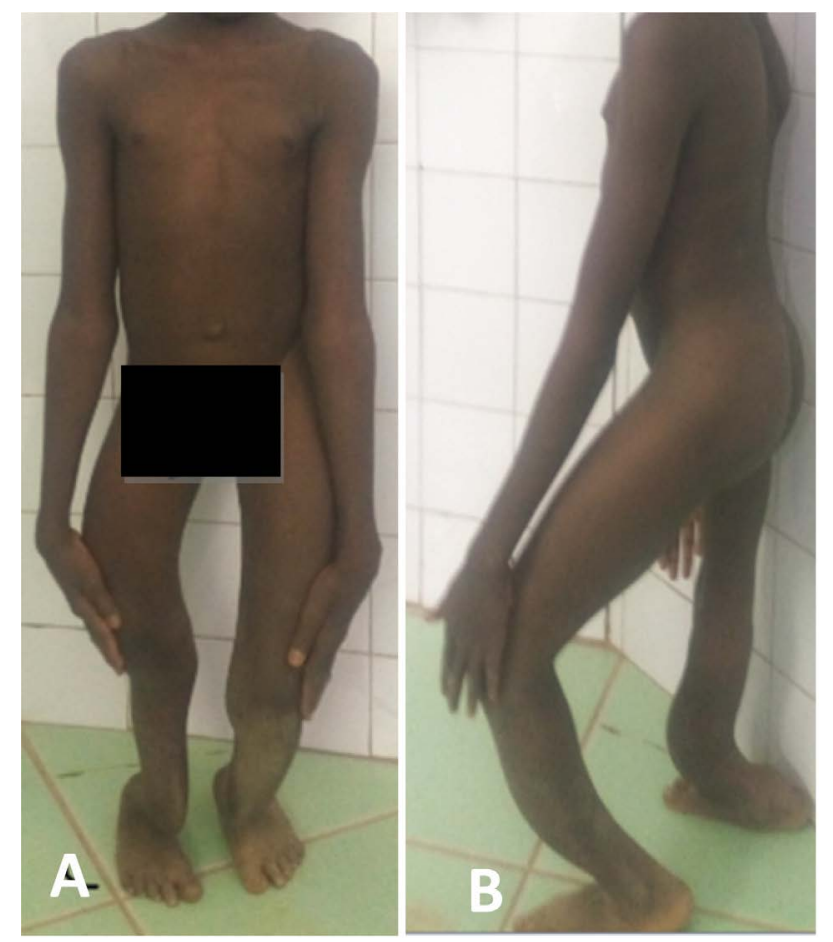

Figure 3. Photo (A) and (B) respectively frontal and lateral view showing deformation of lower limbs occurring on femurs, legs and feet. Shortening of lower limbs compared to upper limbs that reach knee level. 


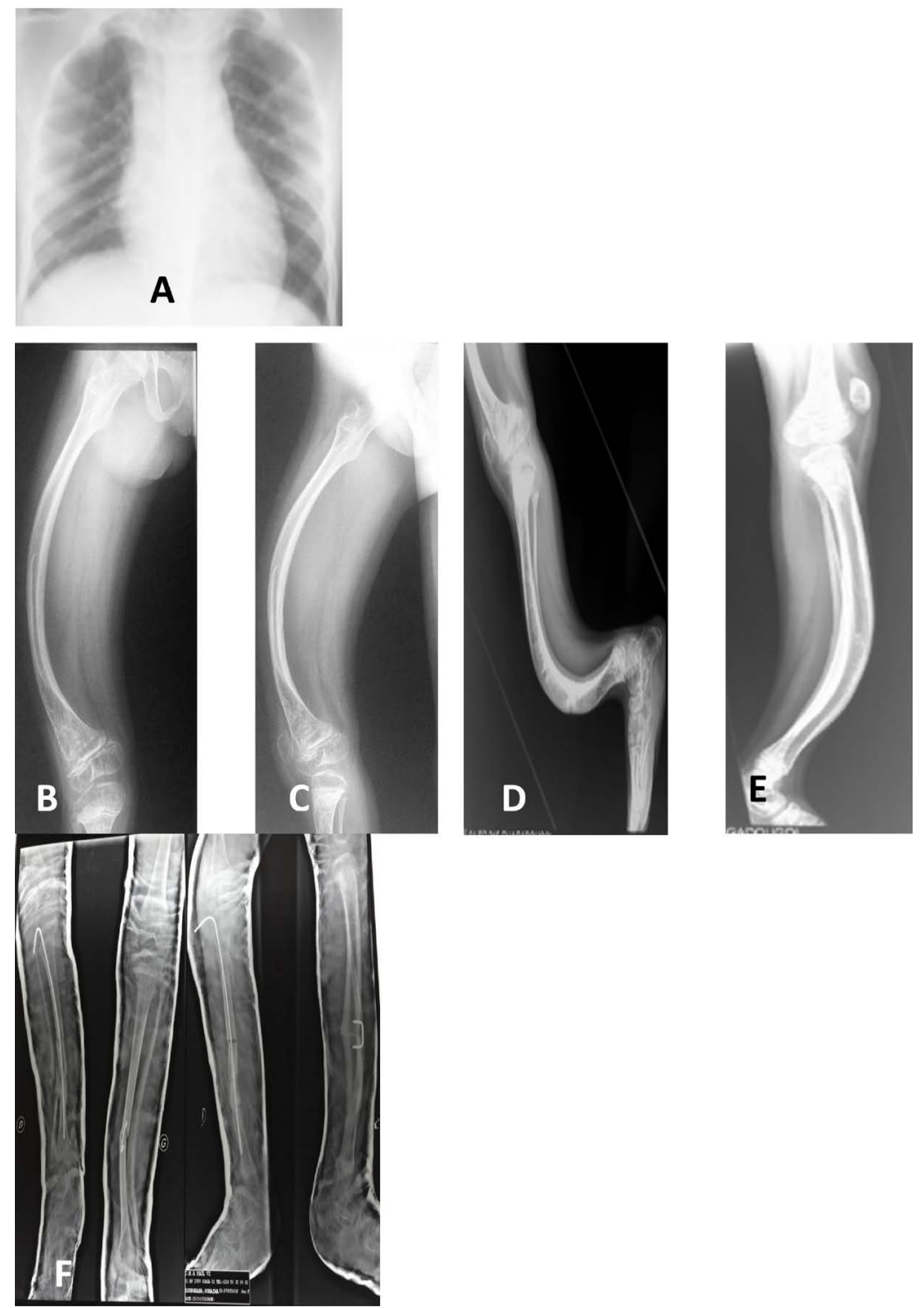

Figure 4. (A) Chest plain film, frontal view: tiny aspect of left posterior ribs; (B) and (C) Right thigh plain films frontal and lateral views: attached butt deformation on femur; (D) and (E) lateral view of right and left legs plain films: saber-shaped deformation, dense metaphyseal tibial bands, long bones metaphysis and epiphysis demineralization. Bony callosities of consolidation; of tarsal and metatarsal bones demineralization; (F) Post-surgery: osteotomy with clip on right and left tibia under plaster.

$\mathrm{cm}$. He had no skeletal or extra-skeletal lesions of osteogenesis imperfecta. ZA had no medical or neonatal history but had delayed motor acquisition, with walking occurring at 5 years after physiotherapy sessions. Clinical examination was unremarkable with no bluish sclerotic and abnormal dentinogenesis (Figure 5). Vitamin D determination showed a vitamin status with 25 hydroxy vitamin D levels at $19.72 \mathrm{ng} / \mathrm{ml}$. X-ray examination showed more diffuse bone demineralization in the metaphyseal-epiphyseal region of the long bones with a curved aspect of femoral diaphysis and deformity of joints (flared metaphysis) (Figures 6(A)-(C)). 


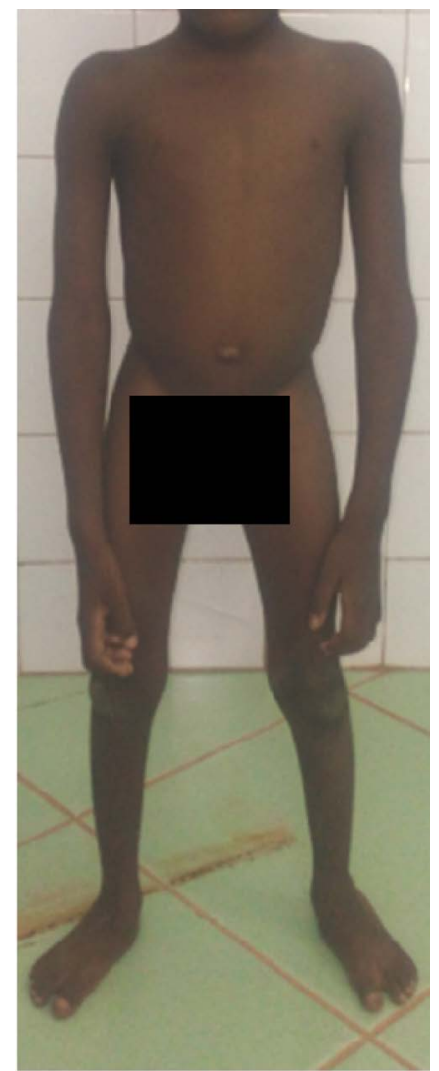

Figure 5. Photo showing shortening of lower limbs.

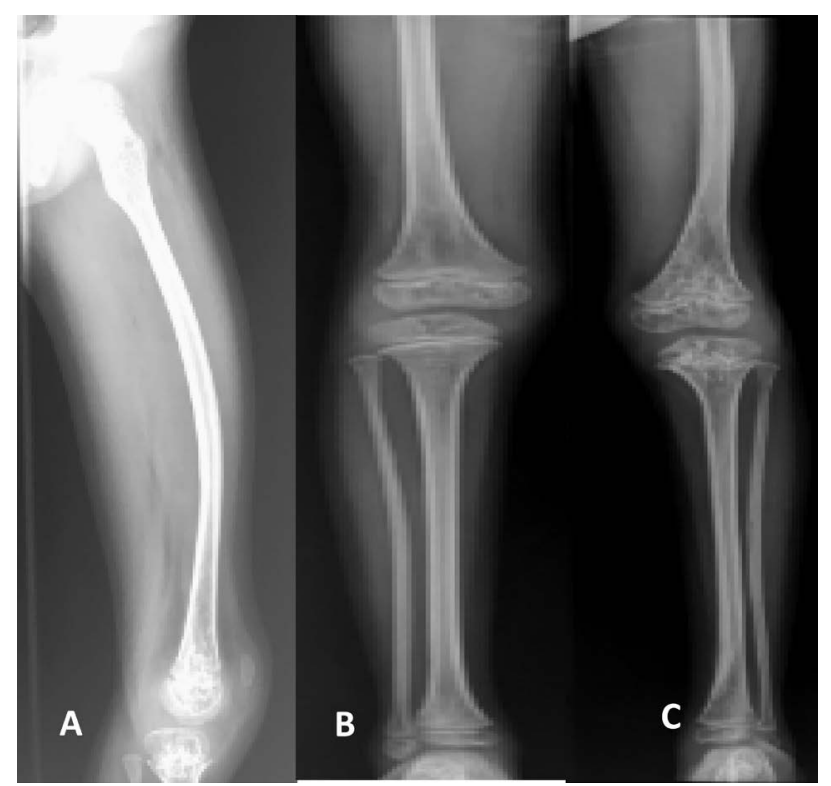

Figure 6. A frontal and lateral view of left thigh plain film and (B), (C): frontal view of both legs plain film showing curvature of femoral diaphysis and prominent bone demineralization with flared metaphysis. Tiny aspect of tibial and femoral diaphysis contrasting with a flared appearance of lower femoral and upper tibial metaphysis producing "trumpet" aspect; Popcorn calcification: scalloped radiolucent areas with sclerotic margins sitting in lower femoral metaphysis, predominant on the left side sometimes on epiphysis. 
The three children were followed up for an initial assessment that classified them according to Sillence classification for rheumatological and orthopedic care management.

The orthopedic treatment which consisted of an osteotomy with staples could be carried out in the two largest who had major deformities in the limbs five months after the radiography and they are in rehabilitation. The youngest follows physiotherapy sessions and normally continues her education. There is no specific medical treatment in place.

\section{Discussion}

These three children have been followed since their childhood by association which tries to schedule their care. We met them during their visit to the radiology department without being able to obtain the initial assessment in imaging that they had already carried out. This constitutes a limit to our study. Nevertheless, we wanted to understand this exhaustiveness of imaging examinations and are limited by the lack of genetic counseling in the mother and father and the lack of genetic research.

Diagnosis of osteogenesis imperfecta is clinical [8]. Anthropometric data study of children with OI showed marked reduction in their height. Short stature with unclear mechanism gets more important while bone fragility is severe [7]. Indeed these three children had size below standard in a discrete way varying respectively of 6.69 inches, 4.33 inches and 4.72 inches which corresponds to 3 DS. Medical imaging contributes to diagnosis through antenatal ultrasound and radiography [6]. Radiography has been the basis of diagnosis in our study as in some authors [8] [9]. Pathological fractures, which are major signs of OI, are frequently associated in varying degrees with bone deformities that are either secondary to vicious callus with angulation, or spontaneous [10].

These deformities have been found in all our patients. Osteogenesis imperfecta is classified into seven clinical types of variable severity according to Sillence [11]. Type II (Porak and Durant disease) and type III are lethal forms that are not compatible with life. Our observations can be classified in type V and VI which are moderate form of autosomal recessive pathology [6] [10]. People with type $\mathrm{V}$ form have fractures as result of minor trauma, normal sclera, interosseous membrane calcification of forearm or leg, dense metaphyseal band below growth plate; hypertrophic callogenesis due to fractures or intramedullary rods; an absence of dentinogenesis. The lack of interosseous membrane calcification can classify this series in type VI marked by fractures following benign trauma, normal sclera, moderate increase of alkaline phosphatase levels, Looser's striae (pseudo fractures) demonstrated on plain films, absence of dentinogenesis, absence of Wormian bones and in addition an absence of rickets [11]. Here again, there is lack of alkaline phosphatase levels elevation. This reflects great heterogeneity of this pathology and allows us to say that this can be a sporadic case. Most of radiological lesions were on pelvic limbs of all children. In Tunisia, fa- 
milial forms of OI represented $17.6 \%$ of cases [12].

Very few family forms have been published in Sub-Saharan Africa [9] [10]. In Ivory Coast, familial involvement of osteogenesis imperfecta (OI) in three cases has also been reported [13]. If we find a female predominance in our series, we cannot however conclude that it is a genetic disease related to sex. It affects men as well as women, without any ethnic predominance [14].

Indeed, genetic studies show that OI is essentially an autosomal dominant disease linked to mutation in gene 17 COL1A1 of chromosome 17 or gene COL1A2 of chromosome 7. There are some cases where the anomaly is not found on COL1A1 or on COL1A2 and then transmission is autosomal recessive [6] [7]. The parents of the children do not present the disease and have no particular pathological history [2] [15] [16]. This is found in this family. Its recessive nature in this series could be explained by involvement of female gender only and in parents with no pathological history and no link of consanguinity. Would she be part of the $7 \%$ of Genin? Germinal mosaicism (7\% of cases) may also be involved (both parents are apparently healthy, but part of the father's sperm or the mother's egg being carriers of the mutation, these parents may have several affected children) [17].

From the point of view of diagnosis and research, it has appeared over the past ten years that other genes than type I collagen could be mutated and could give clinical status of osteogenesis imperfecta. Therefore a new classification of this disease ends up in 12 types. However, WNT1 gene must be mentioned because mutations in its heterozygous state may present as idiopathic osteoporosis [18]. This classification is no longer clinical but genetic highlighting lack of genetic study in our context.

Autosomal recessive osteogenesis imperfecta represents 6 to $8 \%$ and $10 \%$ of all cases of OI and actually mutations in 10 genes are known to be responsible for this form of the disease [7] [16].

Differential diagnosis can be made with juvenile idiopathic osteoporosis, which occurs between 6 and 16 years of age, with imaging of vertebral compression fractures as well as clear metaphyseal bands on the long bones [11]. Normal calcium and phosphate levels in all three cases allow us to eliminate hypophosphatasia which also has a genetic substratum [19].

Treatment of this multi-faceted pathology is medical, surgical and re-educative and depends on the type of OI. It is not property of a single specialty but interdisciplinary. Hence the need for a trained team. Psychological monitoring of children and family is also advised [6].

\section{Conclusion}

OI occurs at variable age according to severity (during intrauterine life for severe forms, in adulthood for less severe forms). In our context, imaging plays a large part in OI diagnosis due to unavailability of bone densitometry, which would have shown collapse of bone mineral density; as well as bone biopsy with histo- 
pathological examination to demonstrate periosteal dysplasia and molecular biology in search of the genetic mutations involved.

Currently, genetic research can be done on leucocytes from a blood sample. There remains the financial question for delivery of direct debits outside.

\section{Acknowledgements}

Thanks to NASSARA association for Burkina for its contribution in care of children.

\section{Consent}

Consent of children's parents has been obtained.

\section{Conflicts of Interest}

The authors declare no conflict of interest.

\section{References}

[1] Womack, J. (2004) Ontogenesis Imperfecta Types I-XI: Implications for the Neonatal Nurse. Advances in Neonatal Care, 14, 309-315.

[2] Aissaoui, T., Slouma, M., Dhahri, R., et al. (2018) Osteogenesis Imperfecta: About a Case with Delay Onset. La Revue de Médecine Interne, 39, A128. https://doi.org/10.1016/j.revmed.2018.03.043

[3] Centre de Référence Maladies Osseuses Constitutionnelles, Filière OSCAR (2016) Protocole National de Diagnostic et de Soins (PNDS) Osteogenese Imparfaite février 2017.

[4] Van Dijk, F.S. and Sillence, D.O. (2015) Osteogenesis Imperfecta: Clinical Diagnosis, Nomenclature and Severity Assessment. American Journal of Medical Genetics Part A, 167, 1178. https://doi.org/10.1002/ajmg.a.36784

[5] Bonafe, L., Cormier-Daire, V., Hall, C., Lachman, R., Mortier, G., Mundlos, S., Nishimura, G., Sangiorgi, L., Savarirayan, R., Sillence, D., Spranger, J., Superti-Furga, A., Warman, M. and Unger, S. (2015) Nosology and Classification of Genetic Skeletal Disorders: 2015 Revision. American Journal of Medical Genetics Part A, 167, 2869-2892. https://doi.org/10.1002/ajmg.a.37365

[6] Chabot, G. and Zeitlin, L. (2004) Classification, Clinical Manifestations and Current Diagnostic Problems of Osteogenesis Imperfecta. Approche interdisciplinaire du traitement de l'ostéogenèse imparfaite chez l'enfant, Montréal, Editions Hôpital Shriners pour enfants, 1-38.

[7] Aubry-Rozier, B. (2015) What's New in Osteogenesis Imperfecta: From Research to Multidisciplinary Management. Revue Médicale Suisse, 11, 657-662.

[8] Kaboré, A., Cissé, A., Yonaba, C., et al. (2015) Ostéogenèse imparfaite: À propos de quatre cas à Ouagadougou (Burkina Faso). Pan African Medical Journal, 22, 69.

[9] Cissé, R., Tapsoba, T.L., Lankoandé, J., et al. (1998) Osteogenesis Imperfecta: About One Case at Yalgado Ouedraogo Teaching Hospital of Ouagadougou (Burkina Faso). Médecine d' Afrique Noire Électronique, 45, 335-339.

[10] Rohrbach, M. and Giunta, C. (2012) Recessive Osteogenesis Imperfecta: Clinical, Radiological, and Molecular Findings. American Journal of Medical Genetics Part C: Seminars in Medical Genetics, 160C, 175-189. 
https://doi.org/10.1002/ajmg.c.31334

[11] Sillence, D.O., Senn, A. and Danks, D.M. (1979) Genetic Heterogeneity in Osteogenesis Imperfecta. Journal of Medical Genetics, 16, 101-116.

https://doi.org/10.1136/jmg.16.2.101

[12] Karraya, M.A., Chaaboumin, M., et al. (1992) L'ostéogénèse imparfaite: A propos de 17 cas. Revue Maghrebine de Pediatrie, 5, 239-244.

[13] Diabate, A.S., Kabas, R.M., Gui-Bile, L.N., et al. (2016) Osteogenesis Imperfecta: Sibship Involvement (about Three Cases). Journal Africain d Imagerie Médicale, No. 8, 1-4.

[14] Imbert, L., Aurégan, J.-C., Pernelle, K. and Hoc, T. (2014) Mechanical and Mineral Properties of Osteogenesis Imperfecta Human Bones at the Tissue Level. Bone, 65, 18-24. https://doi.org/10.1016/j.bone.2014.04.030

[15] De Vernejoul, M.C. (2014) Adult Osteogenesis Imperfecta: Clinical, Radiographic and Therapeutic Aspects. La Lettre du Rhumatologue, No. 405.

[16] Renata, M.M., Nara, S., de Fatima de Faria Soares, M., et al. (2014) Novel Deletion of SERPINF1 Causes Autosomal Recessive Osteogenesis Imperfecta Type VI in Two Brazilian Families. Molecular Syndromology, 5, 268-275. https://doi.org/10.1159/000369108

[17] Genin, G. (2008) Anomalies osseuse constitutionnelles. Sauramps Médical, Paris, 193-204.

[18] Cimaz, R. and Guez, S. (2005) Diagnosis and Treatment of Juvenile Osteoporosis. Archives de Pédiatrie, 12, 585-593. https://doi.org/10.1016/j.arcped.2005.02.007

[19] Linglart, A. and Salles, J.-P. (2017) Hypophosphatasia: The Contribution of Medical Imaging. Archives de Pediatrie, 24, 5S74-5S79. 